\title{
Superando desafios: a simbiose da fé
}

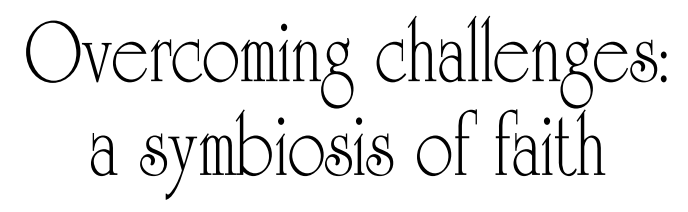

\author{
Cézar Teixeira* \\ Antonio Wardison C. Silva**
}

Resumo: O grande desafio da modernidade é libertar a fé, encarcerada por pensamentos que polarizam e esgotam todo sentido da existência dos seres do planeta. $\mathrm{O}$ objetivo do presente estudo é o de superar este desafio que conduz o homem de fé a se fechar em posições estremas ou se isolar do mundo, ignorando sua própria destruição. A simbiose da fé é uma tentativa de ver esses polos em uma interação, cujo resultado permite ao homem vislumbrar um novo modo de relações entre o homem com a natureza, com os outros homens e com o próprio Deus. Sempre haverá novos horizontes quando se compreende o universal com o particular, o espiritual com o contingente. A fé é capaz de fazer o homem entender essa interação na busca da justiça.

Palavras chave: Desafio; Simbiose; Universal; Espiritual.

Abstract: The modernity's great challenge is to release the faith imprisoned by thoughts polarizing and depleting every meaning of the existence of beings on the planet. The aim of this paper is to overcome this challenge which is leading the man of faith to close himself in extreme positions or isolating himself from the world, and ignoring his own destruction. The symbiosis of the faith is an attempt to see these poles in an interaction, whose result allows the man to discern a new way of relationship between man and nature, another men and God Himself. There will always be new horizons when one does

\footnotetext{
* Doutor em Teologia Bíblica pela Pontifícia Universidade Santo Tomás de Aquino, Roma. É Professor da Faculdade de Teologia da PUC-SP, no Departamento de Teologia Fundamental. ** Doutorando em Filosofia pela PUCSP. Mestre em Filosofia, PUCSP. Graduado em Filosofia e em Teologia.
} 
understand the universal with particular, the spiritual with contingent. The faith is able to make the man does understand such interaction for seeking justice.

Keywords: Challenge; Symbiosis; Universal; Spiritual.

\section{Introdução}

O presente estudo quer refletir sobre possíveis contribuições teológicas para a atualidade, reunindo três temas que ao longo da história tornam-se colunas mestras capazes de sustentar a construção de projetos de pensamentos teológicos. São eles: a reconstrução da totalidade, a espiritualidade e a busca da justiça.

Os temas propostos superam desafios porque estão no centro de todos os conflitos, de todos os medos e de todas as esperanças humanas: a totalidade universal valoriza a contingência, a crítica racional e a diversidade cultural; a espiritualidade valoriza o transversal, que é a vida real e não fuga; a busca da justiça nos coloca diretamente na relação íntima com Deus, porque Ele é Justiça. Os critérios da busca da justiça passam, antes de tudo, pelo chamado à vivência íntima com Deus e à esperança.

A simbiose da fé é uma tentativa de jogar luzes na interação dos polos existentes em cada tema acima descrito. Seria bom que esse esforço fosse requerido por todas as denominações religiosas, como um contributo para que todas as religiões não se tornem meramente produtoras de uma ética legitimadora dos sistemas e instituições vigentes, mas uma reflexão séria e crítica, para que cada geração tenha esperança e compromisso em realizar a boa nova de um novo céu e uma nova terra. Portanto o conceito de totalidade em Cristo reconstrói o caminho da paz dentro da relação do homem com a natureza e com o outro homem. Jesus Cristo nos dá com sua própria vida essa unidade solidária, alimentada por uma espiritualidade profunda e capaz de perceber a verdadeira intenção do Espírito, na busca pela justiça. 


\section{Reconstruindo o conceito de totalidade em Cristo}

Reconstruir a totalidade do universo pode ser uma tarefa que se coloca no plano ideal, mesmo frente às forças de destruição que caracterizam o mundo atual. ${ }^{1}$ Talvez seja demasiadamente ideal dizer também que em Cristo essa totalidade torna-se real, mesmo frente à universalidade exclusiva da pessoa de Jesus Cristo. Ora, o conceito de totalidade aqui sublinhado quer apontar para a interação entre a humanidade e a natureza, na possibilidade de superar a exploração entre ambas e o relativismo entre Jesus homem/Deus. ${ }^{2}$

No primeiro caso, a superação da exploração entre humanidade e natureza vem pelo novo insight que faz gerir o ambiente ecológico com respeito à admiração e preservação como um domínio universal. A totalidade do universo é reconstruída pelo "cuidado", ${ }^{3}$ seja pela exigência de uma ética, seja pela experiência de Deus. Como diz Mancuso, “a religião é 'cuidado' do destino de todos os viventes, paixão da mente e do coração para que o sentido de toda vida seja guardado e a sua existência não tenha sido em vão".

No segundo caso, a superação do relativismo entre Jesus homem/ Deus vem pela simbiose entre o fundamento histórico da vida de Jesus e a interpretação da fé cristã, isto é, o valor da vida humana de Jesus é a essência de valor universal, uma realidade que dá sentido a tudo, universalmente. Com base em Schillebeeckx, a universalidade única de Jesus se constrói na inter-relação entre revelação de Deus e humanidade do ser humano; ambos os polos formam os pilares de uma estrutura linguística capaz de desvelar o verdadeiro rosto da humanidade que se distancia de pretensas ideologias ou abstração de uma universalidade inalcançável. ${ }^{5}$

1 Cf. HOUTART, François. Mercado e Religião. São Paulo: Cortez editora, 2013, p. 40-41.

2 SCHILLEBEECKX, Edward. Jesus: A história de um vivente. São Paulo: Paulus, 2008, 608-611.

3 BOFF, Leonardo. Sustentabilidade: o que: o que não é. Petrópolis/RJ: Vozes, 2012, p. 13: "A escolha é nossa e deve ser: ou formar uma aliança global para cuidar da Terra e cuidar uns dos outros, ou arriscar a nossa destruição da diversidade da vida”.

4 MANCUSO, Vito. Eu e Deus: Um guia para os perplexos. São Paulo: Paulinas, 2014, p. 362-363.

5 SCHILLEBEECKX, Edward. Jesus: A história de um vivente, p. 609. 
A reconstrução da totalidade do universo, então, pode ser compreendida (no nosso entender, esse 'pode ser' refere-se à busca da essência que nos une enquanto seres humanos pensantes e não como imposição) na própria dinâmica da vida de Jesus Cristo, a partir do evento pascal de Cristo que é a manifestação da vitória sobre a morte; da cruz para a salvação; do pecado para a vida em Deus (At 3,$15 ; 2,24$ ). Com Cristo, toda a humanidade herda este dom de salvação: "a morte foi absorvida na vitória. Morte, onde está a tua vitória? Morte, onde está o teu grilhão?” (1Cor 15,54). Cristo, ao romper as potências da prisão, traz a paz do perdão e da reconciliação do homem com Deus (Lc 24,36; Jo 20,20; Rm 5,8-10). Nesse sentido, a ressurreição de Cristo carrega a vida nova para toda a humanidade, pois nele Deus realiza seu plano de amor para os homens. A cruz, que era escândalo, agora tornou-se meio eficaz de salvação. A partir dessa graça, os apóstolos recebem a missão de testemunhar Cristo ressuscitado e de levar, em nome de Cristo, o perdão dos pecados a todos os homens (Jo 20,21-23; Lc 24,44-49; Mt 28,18-20; At 2,32; 37-38; 1Cor 15,1-11).

Para Paulo, a Páscoa significa a ação salvadora de Deus realizada em Jesus Cristo (1Cor 5,7; 15, 20,23). Em Cor 11,23-26, na ceia do Senhor, se tem a prolongação da liturgia pascal veterotestamentária. Para os sinóticos, particularmente em Lucas, a ação de Cristo está apontada para a sua páscoa. Na carta aos hebreus, é aprofundado o significado das obras de Jesus em conexão com o sacrifício da aliança: Cristo é o mediador desta aliança (Hb 8,6; 12,24). Na carta de Pedro, Jesus é apontado como o cordeiro sem mancha, no qual, pelo seu sangue, virá a libertação (1Pd 1,18-19). E em João e no Apocalipse, o significado teológico do evento salvador é ilustrado com a tipologia da páscoa do êxodo: cordeiro pascal que procura a salvação; sinal salvífico erguido na cruz; maior do que Moisés; e único mediador. Toda a cena do Apocalipse é dominada por Cristo, o crucificado ressuscitado na figura de cordeiro. ${ }^{6}$

Portanto, "a páscoa de cristo, é, pois, a realização plena da salvação. Cristo já foi totalmente salvo em plenitude. Porém sua salvação

6 Cf. SARTORE, Domenico; TRIACCA, Achili (orgs.). Dicionário de Liturgia. São Paulo: Paulus, 1992, p. 779-780. 
não o toca somente a si. Ele carrega todos os homens consigo". ${ }^{7}$ Nessa perspectiva, "a fé na ressurreição de Jesus contém a certeza de que, embora Deus não nos livre de sofrimentos terrenos e da morte, ele nos promete que, neles, está junto a nós e, para, além deles, nos leva para dentro de uma nova vida”. ${ }^{8}$

Outra compreensão da totalidade universal passa pelo significado de unidade solidária de todo o gênero humano, concretizada e valorizada pelo indivíduo em um feixe de relações sociais que contribui para a igualdade em todos os níveis: econômico, social, político, cultural e religioso. ${ }^{9}$ Essa compreensão se estende ao Cristo quando do seu assumir plenamente a condição humana, exceto o pecado, isto é, injustiça, corrupção, violência, miséria, fome, doença, morte, etc. Ele partilhou da finitude do homem: sofrimentos, carência, limitação, fome, sede etc. Diferenciou-se do homem não porque carregava a natureza divina, mas porque viveu sua humanidade em plenitude: "ele não é um 'super-homem'; seu ser humano diferente mostra-se justamente no fato de ele se humilhar, estar aí para os outros de maneira libertadora e servir a todos (Mc 10,45)”. ${ }^{10}$

A morte e ressurreição de Jesus Cristo revelam a experiência da dor e da alegria, do sofrimento e da esperança: "Jesus pela morte não somente se distancia de Deus senão que se entrega e se submete à vontade do Pai, por amor a ele e aos irmãos". ${ }^{11}$ Cristo sofre porque se doa à humanidade, a fim de uni-la a Deus e alcançar o perdão dos pecados: Cristo "supera a fragilidade da condição humana, comprometida pelo poder do limite, do pecado e da morte, e a supera precisamente porque assume, compartilha por amor esta fragilidade até o estremo da cruz". ${ }^{2}$ No entanto, o sofrimento de Cristo "não é fim em si mesmo, senão ‘caminho’ ou ‘passo’ (êxodo, páscoa) até a plena comunhão com

\footnotetext{
7 RUBIO, Alfonso Garcia. Unidade na pluralidade: o ser humano à luz da fé e da reflexão cristãs. São Paulo: Paulinas, 1989, p. 366.

8 SCHNEIDER, Theodor (org.). Manual de Dogmática. Vol. I e II. Trad. Ilson Kayser et alii. Petrópolils: Vozes, 2008, p. 384.

9 Cf. HOUTART, François. Mercado e Religião, p. 41.

${ }^{10}$ SCHNEIDER, Theodor (org.). Manual de Dogmática, p. 355.

${ }^{11}$ MORAN, Luis Rubio. El Misterio de Cristo en la historia de la salvación. Salamanca: Sígueme, 1991, p. 358.

${ }^{12}$ Cristo, redentor del hombre. Salamanca: SECRETARIADO TRINITÁRIO, 1986, p. 65.
} 
o Pai e com os irmãos que se realiza na ressurreição".${ }^{13}$ A ressurreição de Cristo revela, pela comunhão com o Espírito, a realidade transcendental de sua própria pessoa. Ele, pelo caminho da cruz, assume as promessas do Pai em uma atitude de amor e liberdade e, por isso, revela o próprio Deus.

\section{A espiritualidade profunda}

A prática de encarcerar o espírito em fórmulas ou expressões imutáveis talvez não seja o único caminho para uma profunda espiritualidade. Por outro lado, considerar o espírito de um mundo sem espírito é convidar nossos contemporâneos a mudar de mundo, ignorando o sentido da vida ou da existência como um todo sem qualquer compromisso. ${ }^{14}$

O homem de hoje tem sede de uma espiritualidade autêntica. Essa necessidade se verifica pelo desejo do homem em entender sua própria identidade e - diante do avanço tecnológico, da técnica e do progresso - de construir sua interioridade: uma interioridade capaz de abrir-se para o outro, de criar comunhão entre as pessoas. Essa experiência conduz o homem a entender-se com o outro, numa relação de comunhão e autenticidade. 0 homem que não é habitado por si mesmo, através de uma intensa vivência da sua interioridade, vive na superficialidade e no movimento das coisas externas.

O cultivo dessa interioridade, que conduz o homem a uma profunda relação com o outro, numa comunhão autêntica, se nutre do espírito, que é a presença ativa do universal em cada ser humano. ${ }^{15}$ Essa relação profunda com outro se realiza na experiência do $e u-t u$, numa dimensão horizontal/vertical: a horizontal se baseia na relação com um parceiro humano; a vertical, com o transcendente, com Deus.

A experiência no espírito proporciona a vivência de liberdade no homem, como alude Paulo: "pois o senhor é o espírito, e, onde se acha o espírito do senhor, aí está a liberdade” (2Cor 3,17). Pois "a

\footnotetext{
${ }^{13}$ Ibid., 1986, p. 67.

${ }^{14}$ Cf. HOUTART, François. Mercado e Religião, p. 42-43.

${ }^{15}$ CONGAR, Yves J. M. Espírito do homem Espírito de Deus. São Paulo: Loyola, 1986, p. 25.
} 
experiência de Deus é experiência de liberdade". ${ }^{16}$ Não obstante, “o espírito não liberta do conteúdo da lei, a saber, do bem, mas liberta da coação das obrigações porque, pela graça e pelo amor, interioriza os seus mandamentos. Desde então os mandamentos promanam de mim. Ajo livremente". ${ }^{17}$ Essa experiência, embora valorize a atitude individual do homem, somente se realiza com o outro, numa profunda comunhão de amor: a "vida a partir do Espírito Santo de Deus significa: aceitar a vida como presente, dar espaço a outra vida, viver em relações, deixar-se libertar e libertar os outros, esperar a consumação de Deus não obstante todo o engajamento". ${ }^{18}$

Viver a vida no espírito não vive "como se", mas como corpo livre e consciente das intenções do espírito. A liberdade dada pelo espírito transcende a experiência privada, da vida interior. Pois não se trata somente de uma experiência espiritual, religiosa ou milagrosa, mas do corpo, "pois aspiramos ao que São Paulo chama de redenção do nosso corpo e que caracteriza como 'a liberdade da glória dos filhos de Deus'”. ${ }^{19}$ Nesse sentido, o corpo também adquire total importância na experiência do espírito: pelo corpo conserva-se a vida do espírito; também pelo corpo, ainda que minúsculo na vida do planeta, o homem torna-se um ser singular. No entanto, muitas são as forças que tendem a desviar o homem da vida do espírito: a autonomia absoluta (representada por teóricos), os falsos messias (o poder político), os ídolos modernos (dinheiro, ciência, conforto, sexo, gnose, mística). Ao contrário, "Se vivemos pelo espírito, pelo espírito pautemos também a nossa conduta" (Gl 5,25).

O espírito, por ser livre, deve romper toda forma de absolutismos e dominação. Ao contrário, o espírito que habita no ser do homem sem cessar, sempre impulsiona a criação e o aperfeiçoamento das coisas. Ora, tudo o que vem do espírito é princípio de comunhão: ${ }^{20}$ ele age na diversidade em plena unidade, em busca do bem comum

\footnotetext{
${ }^{16}$ MOLTMANN, Jürgen. Lo Spirito della vita: per una pneumatologia integrale. Brescia: Queriniana, 1994, p. 125.

${ }^{17}$ CONGAR, Yves J. M. Espírito do homem Espírito de Deus, p. 27.

${ }^{18}$ Cf. SCHNEIDER, Theodor (org.). Manual de Dogmática, p. 490.

${ }^{19}$ CONGAR, Yves J. M. Espírito do homem Espírito de Deus, p. 29.

${ }^{20}$ Cf. CONGAR, Yves J. M. Espírito do homem Espírito de Deus, p. 32.
} 
(1Cor 12,7). ${ }^{21}$ Ora, unidade não é uniformidade e, por isso, requer a diferença. O espírito é, portanto, aquele que reúne os fiéis e os faz membros de um conjunto na diversidade, como também protagonistas de suas próprias práxis.

O espírito é dom de Deus: "é o consumador da auto revelação e auto comunicação de Deus à sua criatura feita à sua imagem”. ${ }^{22}$ Ele é dom de comunhão, revelação do amor do Pai, justiça e santificador do homem. "Nele é possível viver solidificamente em comunhão com Deus, com os nossos semelhantes e com a natureza”. ${ }^{23}$ Por isso, o espírito é a justificação da vida porque nele se encontra toda potência à vida do homem em viver em comunhão com o outro.

\section{A busca da justiça}

A busca da justiça, como desejada por Deus e anunciada por Jesus Cristo, ${ }^{24}$ implica a relação íntima de união do homem com Deus e o imperativo da esperança: na relação com Deus, o homem se nutre da graça dada, uma vez por todas, pelo mistério da ressurreição, a filiação divina e, por isso, capaz de entender o projeto do Reino; no espírito de completa abertura ao Reino, o homem obedece a uma nítida mudança de ordem, que se revigora na esperança. Esses dois

${ }^{21}$ Cf. CONSTITUIÇÃo Lumem Gentium sobre a Igreja. In: Documentos do Concílio Ecumênico Vaticano II. São Paulo: Paulus, 2007, n. 12.

${ }^{22}$ CONGAR, Yves J. M. Espírito do homem Espírito de Deus, p. 43.

${ }^{23}$ MOLTMANN, Jürgen. Lo Spirito della vita, p. 168.

${ }^{24}$ MANCUSO, Vito. Eu e Deus: Um guia para os perplexos, p. 364: Para o autor, "Kant escreve que os seus princípios morais, sem fé em Deus e na imortalidade da alma, seriam 'tirados': não no sentido de que ele não os teria mais respeitado, mas no sentido de que a sua vontade de bem e de retidão seria tirada do trono do mundo, onde, ao contrário, a fé em Deus e na vida futura a mantém firme. Essa fé atesta que há uma dimensão do ser que constitui o pressuposto ontológico do sentir ético, quer dizer, que a vida em si mesma vem pela justiça e vai para a justiça. Aliás, só assim eu explico para mim o surgimento do dever ético: se a vida, de fato, não fosse orientada para a justiça, onde surgiria o sentimento do dever dentro de nós, e em todas as grandes tradições espirituais da humanidade que desde sempre a exprimiram? E porque se deveria perceber esse sentimento como obrigatório e justo? Creio que a ética seja o aflorar à consciência de uma lógica relacional mais ampla e mais harmoniosa que nos trouxe e nos mantém na existência”. 
elementos apresentam-se como critérios necessários para a verdadeira busca da justiça.

\subsection{0 chamado ao dever ético}

Na Sagrada Escritura, o chamado de Deus a uma pessoa, de certa forma, supõe o chamado de todos os homens, ainda que ele não se efetue na vida de todos eles. Ora, Cristo é o verdadeiro Filho Deus: esse chamado é sublime e particular. Mas em Cristo, toda a humanidade herda essa graça, ainda que por adoção: "Ele nos predestinou para sermos seus filhos adotivos por Jesus Cristo" (Ef 1,5); "Porque os que de antemão ele conheceu, esses também predestinou a serem conformes à imagem do seu Filho, a fim de ser ele o primogênito entre muitos irmãos" (Rm 8,29). Por isso, o homem tem o chamado, assim como em Cristo, à filiação, embora de outra natureza.

Mas, ao receber esse chamado, o homem é convidado a configurar-se com Cristo: tornar-se semelhante a ele, embora, como já apontado, na sua condição de filiação divina. Cristo é pedra viva, rei, sacerdote, vítima, filho. Também a humanidade, na sua condição natural, carrega essa realidade: $:^{25}$ "mas vós sois uma raça eleita, um sacerdócio real, uma nação santa, o povo de sua particular propriedade, a fim de que proclameis as excelências daquele que vos chamou das trevas para a luz maravilhosa" (1Pd 2,9). Por isso, temos em comum um mesmo chamado, um mesmo destino.

Cristo comprometeu-se, com toda sua limitação humana, nos projetos do Pai. Sua missão foi árdua, pois foi destinado a atuar no meio de um povo explorado pela organização política da época e, por isso, sedento de justiça, de misericórdia e de libertação. Cristo teve que enfrentar a injustiça, o sofrimento, a perseguição, a rejeição. No entanto, nada o desanimou; revestiu-se der amor, gratidão; comprometeu-se com os mais pobres e injustiçados; renunciou prestígios, honrarias, poder; viveu como as pessoas simples do seu tempo; partilhou sua missão com outros e com os discípulos.

\footnotetext{
${ }^{25}$ Cf. SEGARRA, Juan Antonio. El misterio de Cristo: introducción dogmática a la vida espiritual. Madrid: Razon y fé, 196, p. 189-190.
} 


\subsection{Esperança}

O homem que adere a fé em Cristo e procura participar do seu mistério é um ser de esperança. A esperança do homem é, fundamentalmente, o próprio Cristo. Não obstante, ela torna-se viva pela expectativa do Reino de Deus. No Evangelho, o Reino de Deus, por várias vezes, é mencionado como conteúdo da pregação de Jesus (Mc 1,14-15; Lc 4,44; At 1,3; 8,12; 20,25). O "Reino de Deus" aparece 32 vezes no evangelho de Lucas. No evangelho de Mateus, o Reino tem outro predicativo: dos céus (Reino dos Céus), onde também aparece 32 vezes. No entanto, essas duas terminologias são semelhantes.

Mateus, em particular, utiliza "Reino dos céus" por não poder, diante dos judeus, fazer referência direta a Deus, pois os judeus julgavam algumas pessoas de falarem o nome de Deus em vão. Fundamentalmente, o "Reino de Deus" é a esperança no "dia do Senhor", na chegada de uma nova ordem, onde se manifestará a vontade de Deus: essa é a esperança de Israel e da nova vida em Cristo. "Por mais surpreendente que pareça, a esperança cristã não consiste em 'ir aos céus', mas em que seja feita a vontade de Deus 'como nos céus', assim também na terra"”. ${ }^{26}$

Nessa perspectiva, a esperança no Reino não se limita à dimensão espiritual e, por isso, abrange a realidade como um todo. Caso o "Reino de Deus" estivesse compreendido como realização num "outro lugar” (num espaço físico diferente), não haveria motivo de se preocupar com o mundo ou a sociedade humana. Ao contrário, a esperança do homem, do Reino, consiste na vinda de um mundo melhor, repleto de justiça, de misericórdia, de compaixão e, por isso, de esperança de uma nova ordem, em que predomine a vontade de Deus. O Reino de Deus é a promessa e, ao mesmo tempo, realidade divina. Algumas vezes, Jesus fala do Reino "entre vós” (Lc 17,21); outras, daquele que "há de vir" (Mt 4,17).

A esperança no Reino, portanto, está além de uma mudança de espaço ou de juízo final, castigador, pois representa uma nova ordem, como afirma Isaías: “então o lobo morará com o cordeiro, e o leopardo

\footnotetext{
${ }^{26}$ GONZÁLEZ, Justo L; PÉREZ, Zaida M. Introdução à Teologia Cristã. Trad. Silvana Perrella Brito. Santo André: Academia Cristã Ltda, 2006, p. 230.
} 
se deitará com o cabrito. O bezerro, o leãozinho e o gordo novilho andarão juntos e um pequenino os guiará” (Is 11,6). Para Paulo, o Reino representa não somente a salvação do homem, mas a restauração de toda criatura (Rm 8,21-23). Assim, o Reino de Deus tem abrangência universal, onde toda a criação cumprirá a vontade de Deus. ${ }^{27}$

A partir dessa compreensão, entende-se o alcance do Reino: a esperança de um novo céu e de uma nova terra (At 21,1). Ora, a ordem do mundo atual se caracteriza pelo poder, pela ganância, pelo interesse, pela opressão, pela exploração. Ao contrário, Cristo anuncia a humildade, o serviço, a doação e a justiça (Mc 10,42-45). A esperança na justiça é uma característica fundamental para entender a esperança no Reino. Assim fala o salmista: "amor e verdade se encontram, justiça e paz se abraçam" (Sl 85,11); nas palavras de Jesus: "Felizes os que têm fome e sede de justiça, porque serão saciados” (Mt 5,6).

O cristão, ao depositar sua esperança no Reino, torna-se um cidadão desse Reino (Fl 3,20; Hb 11,13-16); vive da esperança e de atitudes que expressam a existência do Reino; vive segundo aquilo que confia; ao esperar o Reino, vive de acordo com o Reino, com sinais visíveis e cheios de fé. "O Senhor Jesus, depois de ter orado ao Pai, chamou a si os que ele quis e escolheu os doze pra estarem com e ele e para os enviar a pregar o reino de Deus”. ${ }^{28}$

\section{Conclusão}

O grande desafio do homem contemporâneo é viver sua fé no meio de realidades conflitivas, tendo como consequência, em grande parte, práxis de fugas, por ver sua fé atolada em um ativismo social ou em um espiritualismo, em que muitas vezes o afasta da pertinente utopia, transmitida por Jesus Cristo nos evangelhos, de um novo céu e de uma nova terra. Isso não implica necessariamente o enfraquecimento da fé, mas um modo de alimentar e viver essa fé.

GONZÁLEZ, Justo L; PÉREZ, Zaida M. Introdução à Teologia Cristã, p. 234.

${ }^{28}$ CONSTITUIÇÃO Lumem Gentium sobre a Igreja, n. 19. 
Nessa perspectiva, porém, se faz necessário uma compreensão da totalidade do mistério de Jesus Cristo, que culmina em uma espiritualidade profunda, dada por uma íntima união com Deus, e busca da efetivação do Reino, vigorada pela esperança pessoal e coletiva. Dessa forma, é possível ver a simbiose entre o universal e o particular, entre o divino e o humano e, finalmente, entre o espiritual e o corporal, o real ou o histórico.

A compreensão da totalidade em Cristo vem para descomplicar o próprio conceito de totalidade ou de universalidade, que só pode ser alcançado por seres superdotados. Contudo, não basta também afirmar que o Jesus histórico é o Cristo. Esse homem/Deus não é mágico, mas o Deus, a totalidade, o transcendente que veio participar do particular, do imanente, do contingente etc. As coisas que Jesus fez no particular, são universais porque veio de uma dimensão universal, Deus, que entrou em nossa humanidade para nos tornar mais humanos e romper todas as barreiras que impede a existência de todos os seres, sejam elas em nível econômico, social, político, cultural ou religioso. Por isso, humanidade e natureza, universal e particular entram em perfeita simbiose na pessoa de Jesus Cristo.

Uma espiritualidade compatível com esse novo desafio não pode ser embasada na experiência do "faz de conta que" ou "como se fosse", mas na experiência do espírito que nos fortalece para transformar o mundo e para compreender o sentido da vida ou da existência como um todo, por meio do compromisso com o outro.

É a busca da justiça para todos que a simbiose da fé poderá contribuir para o crescimento da humanidade dos seres humanos, abrindo novos caminhos, deixando para trás a velha trincheira entre o social e o espiritual, em que ambas ora se polarizam entre si, ora se esgotam. A diferença para a verdadeira busca vem pelo critério do chamado ao dever ético, isto é, Deus chama o homem para estar com ele e nutrir-se de sua própria natureza que é Justiça. Outro critério é a esperança que faz o homem se abrir sempre para mudar o mundo, no eterno sonho do novo céu e da nova terra. 


\section{Bibliografia}

BOFF, Leonardo. Sustentabilidade: o que: o que não é. Petrópolis/RJ: Vozes, 2012.

CONGAR, Yves J. M. Espírito do homem Espírito de Deus. São Paulo: Loyola, 1986.

CONSTITUIÇÃO Lumem Gentium sobre a Igreja. In: Documentos do Concílio Ecumênico Vaticano II. São Paulo: Paulus, 2007.

Cristo, redentor del hombre. Salamanca: SECRETARIADO TRINITÁRIO, 1986.

DIETRICH, S. de. O Desígnio de Deus: itinerário biblico. São Paulo: Loyola, 1977.

GONZÁLEZ, Justo L; PÉREZ, Zaida M. Introdução à Teologia Cristã. Trad. Silvana Perrella Brito. Santo André: Academia Cristã Ltda, 2006.

HOUTART, François. Mercado e Religião. São Paulo: Cortez editora, 2013.

MANCUSO, Vito. Eu e Deus: Um guia para os perplexos. São Paulo: Paulinas, 2014.

MOLTMANN, Jurgen. Lo Spirito della vita: per una pneumatologia integrale. Brescia: Queriniana, 1994.

MORAN, Luis Rubio. El Misterio de Cristo en la historia de la salvacion. Salamanca: Sígueme, 1991.

RUBIO, Alfonso Garcia. Unidade na pluralidade: o ser humano à luz da fé e da reflexão cristãs. São Paulo: Paulinas, 1989.

SARTORE, Domenico; TRIACCA, Achili (orgs.). Dicionário de Liturgia. São Paulo: Paulus, 1992.

SCHILLEBEECKX, Edward. Jesus: A história de um vivente. São Paulo: Paulus, 2008.

SCHNEIDER, Theodor (org.). Manual de Dogmática. Vol. I e II. Trad. Ilson Kayser et alii. Petrópolils: Vozes, 2008.

SEGARRA, Juan Antonio. El misterio de Cristo: introducción dogmática a la vida espiritual. Madrid: Razon y fé, 1964. 